\title{
Conferencia
}

\section{Transformaciones del poder en la sociedad moderna Desafíos para la Iglesia católica}

\author{
Eduardo Valenzuela \\ Instituto de Sociología, Facultad de Ciencias Sociales \\ Pontificia Universidad Católica de Chile \\ evalenzc@uc.cl
}

Quisiera centrarme en algunos puntos que pueden ser útiles para la discusión sobre el uso del poder en la sociedad y en la Iglesia actual. El poder consiste en la capacidad de determinar la voluntad de otros a través del uso de sanciones negativas. Existen muchas maneras de obligar a otros a hacer lo que -en principio- no quieren hacer (porque para hacer lo que se quiere no se necesita obligar a nadie): se puede cambiar la voluntad de alguien a través de la persuasión, por ejemplo, o del dinero y de los incentivos económicos como recomiendan actualmente los economistas. Pero la voluntad permanece en muchas ocasiones irreductible y se requiere el uso de sanciones negativas. Tales sanciones pueden abarcar un abanico muy amplio de posibilidades, la privación de libertad, un despido, una evaluación negativa, las penas del infierno, entre muchas otras. Lo propio de todo castigo es que descansa en último término en la capacidad de ejercer la fuerza sobre otros y por ello el poder remite siempre al ejercicio de la coacción y de la violencia (aunque casi siempre basta una ligera amenaza para conseguir el resultado deseado). En las sociedades modernas el uso del poder ha sufrido varias transformaciones de importancia. La más conocida es la especificación del uso del poder en el sistema político y la monopolización creciente del uso de la fuerza en manos del Estado. El poder constituye el medio de comunicación exclusivo de la política, sólo el Estado puede obligar a otros a través de sanciones respaldadas en el uso de la fuerza, algo que los ciudadanos hemos concedido crecientemente a condición de que el Estado quede él mismo obligado por las normas que impone (que fue la principal razón por la que se eliminó al Rey durante la revolución francesa, puesto que era el único obstáculo para reconocer la igualdad de todos ante la ley). En esto consiste el fundamento del contrato político moderno que llamamos un Estado consti- 
tucional y democrático. Originalmente la expropiación de la capacidad de las personas de utilizar la fuerza se expresó en la suspensión del derecho de portar armas (que sólo quedó en pie por razones particulares en la Constitución norteamericana, con consecuencias desastrosas que se lamentan hasta hoy). Norbert Elías llamó a esto el "proceso civilizatorio" a través del cual las personas - privadas de la capacidad de utilizar armas- tuvieron que relacionarse de un modo cada vez más pacífico y eliminar la agresión en las relaciones sociales ordinarias. Esto tuvo un impacto decisivo en la aparición del amor cortés y del arte de la seducción (que reemplazó al rapto de la novia y las diversas formas de coacción matrimonial que imperaron en el mundo antiguo), pero la eliminación de la violencia de género ha sido un proceso largo que todavía no culmina, como lo muestra el reciente movimiento feminista contra el abuso masculino (cuyo lema es justamente "no=no", es decir, la insistencia en que el hombre no puede obligar a la mujer a hacer algo que ella no quiere hacer, y que califica como violencia simbólica cualquier presión sobre la voluntad de otro). Otra esfera en que se ha eliminado recientemente la capacidad de las personas de ejercer violencia ha sido el castigo parental de los hijos que hasta hace unas pocas generaciones utilizaba corrientemente la fuerza (en el mundo antiguo incluso los padres retenían el derecho de matar a su hijo), algo que se ha ido suavizando en el sentido civilizatorio de Elías hasta hoy en día, en que el uso de la fuerza contra los hijos está apenas justificado y crecientemente controlado por el Estado y las reglas jurídicas. Algo del declive de la autoridad del padre sobre sus hijos en la familia actual tiene que ver con la suspensión del castigo físico dentro de la casa que, por lo demás se ha vuelto perentorio en las escuelas (ningún profesor podría hoy levantar la mano contra alguno de sus alumnos). El proceso civilizatorio ha continuado con las aprensiones modernas respecto del maltrato animal, el que sólo están destinadas a expandirse en el futuro próximo, hasta llegar quizás a la proliferación de una dieta vegetariana y que - dicho sea de pasoacerca mucho la sensibilidad religiosa moderna (sobre todo de las nuevas generaciones) a la ahimsa del budismo, la obligación de no dañar a ningún ser vivo por insignificante que sea (el arhat se hace a un lado incluso al paso de una hormiga). ¿Ha desaparecido del todo el uso de la violencia en las relaciones sociales? La violencia sólo se considera legítima cuando es ejercida por el Estado bajo condiciones debidamente reguladas por el aparato jurídico, que incluyen sobre todo la obligación de que quien legisla y tiene la capacidad de imponer la ley ("enforce the law" se dice en inglés para identificar el poder ejecutivo, al que dota de fuerza el cumplimiento de la ley) se obligue 
a sí mismo a cumplirla. En el mundo antiguo el Rey hacía leyes de las que expresamente se exceptuaba él mismo (en las monarquías sagradas de otrora incluso de la regla del incesto), algo que se extiende hacia la autocomprensión que tienen usualmente las élites o los estratos superiores, cuya distinción estatutaria consistió casi siempre en estar por encima de la ley, es decir, en poseer privilegios. El privilegio fue justamente la capacidad de algunos de no cumplir con la ley que rige para todos los demás. El abuso de poder en las sociedades contemporáneas debe entenderse de esta manera como la conciencia de todo estrato superior de estar exceptuado de las normas que impone a otros, lo que abarca el clericalismo que incluye no sólo la vista gorda, es decir, la tolerancia hacia las faltas de los sacerdotes que no se tiene respecto de los fieles, sino sobre todo la pretensión de que los sacerdotes (o al menos la institución eclesiástica) es santa y está libre de pecado, y por consiguiente exenta de la necesidad de la confesión. La vehemencia con que hoy se ataca la corrupción del poder político (y de cualquier otra forma de ejercicio de la autoridad) y el celo moderno en vigilar escrupulosamente los actos de la autoridad tiene este mismo sentido de controlar al controlador (o en el caso sacerdotal de perdonar al que perdona). El que legisla debe estar sujeto a la legislación que él mismo dicta, y el que tiene capacidad de obligar debe quedar igualmente subsumido en la obligación que es capaz de ejercer sobre otros. Este proceso se identifica con la desacralización del poder que se ha completado casi enteramente en los tiempos modernos. Los atributos propios de lo sagrado que comprendieron de manera precisa la capacidad de exceptuarse de la norma (como en el caso del incesto real) han dejado casi totalmente de asociarse al poder en cualesquiera de las formas que se ejerza. De hecho, el poder sagrado consistió precisamente en esto: no sólo en la capacidad de determinar la voluntad de otros de manera concluyente, sino en la condición específica de quedar exceptuado de esta determinación, lo que hacía al monarca sacro y efectivamente poderoso.

El uso legítimo de la violencia queda radicado en el sistema político jurídicamente regulado y la capacidad que retengan las personas de utilizar sanciones negativas queda sujeto a demandas y apelaciones jurídicas (como en el caso de los despidos laborales o de las sanciones administrativas que aplican las universidades por faltas disciplinarias contra sus profesores o estudiantes). Muchos autores han notado, sin embargo, que incluso la autoridad política se abstiene crecientemente de usar la amenaza y la violencia, y lo hace con reticencia creciente. También esto forma parte del proceso civilizatorio descrito esta vez por 
Michel Foucault que estudia detalladamente los cambios en la penalización del crimen en la época moderna, y que han quedado graficados en la invención de la guillotina como un instrumento que permitía la muerte incruenta del criminal y que reemplaza a la antigua justicia del Rey que culminaba, por el contrario, en el suplicio público del criminal ante la vista a la vez complacida y aterrorizada de todo el mundo. La desaparición progresiva de la tortura y de las penas de tormento (que abundaron asimismo en la persecución del crimen religioso) y su reemplazo por la cárcel y la reclusión moderna, es decir, el movimiento de humanización de la pena descrito por Foucault, revela este ocultamiento de la remisión a la violencia que caracteriza siempre al poder en el mundo moderno. El poder político tiene las atribuciones y la capacidad legítima de utilizar la fuerza, pero evita hacerlo todo cuanto pueda e interviene (como la policía antimotines en las manifestaciones que se descarrilan gravemente) solamente en los casos extremos, e incluso en tales casos muchos dudan seriamente de su legitimidad (como sucede con la aprobación creciente que recibe la abolición definitiva de la pena de muerte incluso para crímenes horrendos). Hannah Arendt señala que la violencia constituye una manifestación de la impotencia del poder y de su incapacidad de obligar a alguien a hacer lo que está prescrito: el empleador despide a alguien cuando no ha conseguido que el trabajador se desempeñe adecuadamente, así como el Estado condena a un delincuente porque no ha conseguido que actúe conforme a las normas socialmente aprobadas. La cárcel es uno de los símbolos más poderosos del fracaso del Estado, y deberemos quizás acostumbrarnos a que las demandas de desprisonización se vuelvan más frecuentes, a pesar de que el público sigue siendo en muchos sentidos la turba linchadora de la antigua justicia real. Pero también la sensibilidad moderna contra el poder y el uso de la violencia es propia del contrato original mediante el cual los ciudadanos aceptan despojarse ellos mismos de su capacidad de ejercer poder sobre otros y otorgar esa capacidad al Estado, a condición de que la autoridad lo utilice para el bien común, bajo formas y modalidades que puedan ser debidamente controladas. Debe advertirse, sin embargo, que la violencia puede ser utilizada sin poder, es decir, al margen de todo consenso y de cualquier control institucional. Por ejemplo, la violencia que se ejerce en nombre de los más pobres y desamparados, la violencia indígena, etc. Esta violencia sin poder tiene más adeptos de los que convendría. De hecho, hoy se rechaza más la violencia que proviene del poder (aunque 
sea legítimo) que aquello que se ejerce por los que no lo tienen. Por ende, no existe una condena de la violencia a ultranza.

La Iglesia ha tenido -y tiene todavía sobre todo en los países que han conocido la unanimidad religiosa- la reputación de ser una institución de poder. Alguna vez la religión tuvo la capacidad de convertir sus creencias en leyes imperativas para toda la sociedad y dotar a esas normas de la fuerza necesaria para imponerlas a través de su asociación con el Estado. Actualmente el sistema religioso y el sistema político están suficientemente diferenciados para que cualquier pretensión de construir leyes a través de creencias religiosas quede sancionada prácticamente como corrupción (de la misma manera como sucede con la selección académica en la operación del sistema de la ciencia al interior de las universidades). El intento de traducir creencias religiosas en derecho natural y hacer coincidir religión y razón ha sido el último esfuerzo de la religión (específicamente del catolicismo) por mantener abierto el canal hacia el sistema político, sobre todo en un contexto en que debe aceptarse la neutralidad religiosa del Estado y el pluralismo de los valores. Con todo, la capacidad de la religión de intervenir favorablemente en el proceso legislativo del Estado moderno se ha vuelto casi nula. Hoy en día, por ejemplo, la línea divisoria entre quienes aceptan o rechazan el aborto es casi enteramente religiosa (sólo las personas con creencias religiosas profundas rechazan el aborto lo que significa que la razón natural es incapaz de hacer una diferencia). La pérdida de acceso religioso al poder político es el principal motivo de la reacción católica que se prepara para vivir en el arca en medio del diluvio (tal como aparece, por ejemplo, en La Opción Benedictina, de Rod Dreher). El repliegue sectario de la religión mediante la formación de pequeñas comunidades impermeables al mundo exterior y que cultivan un modo de vida contracultural (que incluye sobre todo la desescolarización de los niños y el rechazo de la moderna tecnología de las comunicaciones) aparece como una opción abierta también para un catolicismo decepcionado de su pérdida de poder.

Por otra parte, la religión retuvo mucho tiempo la capacidad de ejercer sanciones negativas privando a los fieles de los bienes de salvación que ofrece, condenándolos al fuego eterno, por ejemplo. El temor de Dios fue utilizado con profusión incluso en la eucaristía católica, al decir de los historiadores que han documentado el terror de los campesinos medievales cuando el sacerdote levantaba la hostia consagrada, en un sentido que calza con la experiencia descrita por Rudolf Otto para definir lo sagrado como 
una conjunción entre lo que atrae y repele, encanta y aterroriza, al mismo tiempo. La experiencia numinosa de la eucaristía desaparece en la devoción moderna bajo el impulso de la eucaristía frecuente y de devociones como la del Sagrado Corazón de Jesús que aclaran la naturaleza amorosa y benevolente de la presencia eucarística. La desacralización de los objetos y de la autoridad religiosa han jugado ciertamente un rol decisivo en la moderna visión beatífica de Dios ("lento a la cólera y rico en misericordia"). Pero siempre quedó en pie el Diablo. En el catolicismo moderno se vuelve más apremiante el sacramento penitencial que ha sido reputado como el mecanismo de control eclesiástico más eficaz de que ha dispuesto jamás una religión (véase sobre todo a Jean Delumeau, La Peur en Occident, para una visión amplia de este asunto). Es cierto que la confesión católica actuó bajo la distinción entre atrición (por temor de Dios) y contricción (por amor a Dios) y consideró siempre que la confesión se validaba a través de un acto de genuino arrepentimiento de la falta cometida. La confesión asimismo operaba bajo un régimen de indulgencia y perdón muy amplio denunciado por el rigorismo católico, por ejemplo, en la famosa controversia entre Pascal y los jesuitas franceses. Pero la confesión frecuente y la ampliación del catálogo de pecados hacia faltas incluso nimias que impera todavía en el protocolo penitencial moderno, que contradijo la confesión anual y limitada a pecados graves del catolicismo antiguo, y sobre todo la confesión de niños, basada por entero en el temor de Dios, entregaron a los clérigos una enorme capacidad de control moral sobre la población. ¿Bajo qué condiciones se disipó casi totalmente el temor de Dios en la devoción moderna? En la última versión de la American Fears Survey (SSSR Research, 2018) apenas el $14,2 \%$ de los norteamericanos decía sentir temor a Dios, un $23,7 \%$ al infierno y una cifra similar al diablo. El temor religioso se encuentra muy por detrás de los temores sociales o medioambientales (entre los cuales se cuenta crecientemente la expectativa de que el planeta se extinguirá en una versión secularizada del apocalipsis y del fin de los tiempos) que hoy llevan con mucho la delantera en la sensación de inseguridad de la población En el declive de la confesión se anida la diferenciación creciente entre el sistema de la moral y el sistema religioso que se fundó en la noción de pecado como falta que se comete contra Dios (y no sola ni principalmente contra un hermano, de hecho la penitencia confesional no fue nunca reparatoria) y, sobre todo en la capacidad de vincular la falta con las expectativas de salvación. Pero la distensión moderna de la angustia soteriológica (todos estamos salvados en la misericordia de Dios) y la completa disociación entre comportamiento 
moral y salvación religiosa han vuelto casi inútil la confesión de los pecados al menos en la mentalidad del creyente común y corriente y han despojado a los sacerdotes de mucho del poder que otrora tuvieron como dispensadores y administradores de la gracia divina. La transformación de la eucaristía que elimina la estructura del poder sagrado y actualmente de la confesión que ofrece una perspectiva amplia y profunda de la misericordia de Dios han replanteado completamente la perspectiva del poder en la Iglesia, en cuanto la han despojado casi completamente de su capacidad de producir sanciones negativas.

Otra dimensión del poder que ha cambiado es la disolución del soberano, es decir, de la concentración del poder en una sola persona que introduce la metáfora de los pasillos del poder (o de la corte) atestados de consejeros, asesores, ministros y confesores que conducen hacia "un único individuo humano" como señala Byung-Chul Han. En la sociedad moderna el poder es una magnitud relativa. Cada vez menos el poder aparece asociado con los otros dos atributos de la jerarquía social, la riqueza y el prestigio. Todavía el Rey de Francia no dudó en destituir a su ministro de Hacienda después de advertir que su palacio era todavía mejor que el suyo. Las democracias modernas han reducido además la influencia del dinero en la ascensión al poder y han limitado las posibilidades de enriquecimiento a costa del poder. Algunas figuras como Lincoln en Estados Unidos y Juárez en México, que consiguieron llegar a la cúspide del poder desde abajo -que, por lo demás, ha sido también frecuente en el caso de las dignidades eclesiásticas- han sido poderosos símbolos de la desconexión entre riqueza y poder. El último eslabón de este descentramiento ha sido la abrumadora pérdida de prestigio del poder en las democracias parlamentarias modernas que dejó de suscitar hace mucho tiempo esa fascinación aterradora de lo numinoso de R. Otto, pero que también ha dejado de estar rodeado de la pleitesía, adulación y admiración que se reservaba otrora a los poderosos. Todavía permanecen algunos cargos carismáticos en la cúspide del Estado -entre los cuales debe contarse el cargo pontifical en la Iglesia católica- pero es posible que su prestigio se sostenga en una proporción inversamente proporcional al poder que detentan, como en el caso de los reyes europeos. Al menos el prestigio religioso, es decir la santidad, abunda por doquier entre quienes nunca han detentado un cargo eclesiástico, aunque la tendencia moderna de santificar a los Papas desmiente esta rica tradición católica de desconectar santidad y poder. Como sea, todo aquel que decide está expuesto hoy en día a perder más que a ganar prestigio, tal como en el mundo antiguo los jefes se arruinaban 
en el ejercicio de su cargo, obligados en efecto a dar lo suyo para mantener la lealtad de sus seguidores.

Donde mejor se percibe la disolución del soberano, sin embargo, es en el hecho de que el poder es algo que se gana y se pierde. Esto ocurre sobre todo en el espacio del poder que se distribuye discretamente. Se tiene poder en un determinado rol, pero se pierde completamente en otro. Hasta el más poderoso debe lavar los platos en su casa o al menos debería hacerlo. Antiguamente el soberano era poderoso dentro y fuera de su casa y donde fuera, ocupaba la cabecera. Hoy ha desaparecido el celo con que se conservaba la dignidad del poder en cualquier situación, aun aquellas degradantes como la que adoptaba el Rey enfermo ante las manipulaciones humillantes de su médico, la situación por excelencia en que perdemos el poder casi por completo. Nunca se ha estado más atento que hoy a la exigencia de que el gobernante se comporte como un ciudadano cualquiera fuera de su cargo. Otra dimensión en la que el poder se experimenta como una magnitud contingente en la dimensión temporal. Nadie está destinado a gobernar para siempre, como sucedía en el mundo antiguo. Los cargos se proveen por un período acotado y previamente definido, algo que se muestra en la sobriedad de las ceremonias de investidura que están destinadas a subrayar más la fugacidad que la estabilidad del cargo. Ejercer el poder con la expectativa de que algún día se perderá, cambia totalmente la forma de ejercer el poder que, en su conjunto, pierde la arrogancia y el despotismo de antańo, incluso por el solo hecho de su finitud. La costumbre francesa de conservar la dignidad del cargo - por ejemplo, continuar tratando al que ha sido presidente como tales un mentís a la tradición democrática que subraya, por el contrario, que el cargo se pierde irremediablemente, incluyendo el respeto y la deferencia que se le debía. El poder es hoy un atributo que se separa y se dispersa, se gana y se pierde, se posee y se deja de poseer. Como dice Han, es un atributo que se separa de la voluntad humana o, como gustan decir los sociólogos, en el poder no está la persona sino el cargo, de manera que el poder deja de ser el lugar de la autoafirmación de sí mismo como hubiesen deseado Nietzsche y Schmitt, algo que se conserva oscuramente todavía en la definición del poder como liderazgo, pero que se pierde por completo en la definición evangélica del poder como servicio, que conmina a ser como el Hijo del Hombre que "no vino para ser servido, sino para servir, y para dar su vida en rescate por muchos". (Mt 20:27-28). El manual de ejercicio monástico del poder escrito por San Benito -que debe considerarse un verdadero tratado de ciencia política- ofrece indicaciones que son provechosas hasta el día de 
hoy. San Benito, en efecto, se planteó el desafío de constituir una autoridad que permitiera darle estabilidad a una comunidad humana compuesta a la sazón por monjes dispersos e indisciplinados. De la institución del abad - una autoridad electa por la comunidad por un tiempo determinado- se dice que "más le corresponde servir que presidir", que haga prevalecer más la misericordia que la justicia y que "procure ser más amado que temido" (LXIV de la Regla de San Benito). El abad "reprende, exhorta y amonesta", algo que incluye la severidad de castigo físico en ocasiones extremas, pero el secreto de la autoridad del abad que recuerda San Benito es que su misión no es dirigir los cuerpos, sino "que ha tomado sobre sí la responsabilidad de dirigir almas" (II de la Regla de San Benito). 